\title{
Feasibility of endoscopic mucosa-submucosa clip closure method (with video) $\square$
}

\section{(ㄷ)(1) $\odot$}

Authors

Toshihiro Nishizawa', Shigeo Banno², Satoshi Kinoshita ${ }^{1}$, Hideki Mori², Yoshihiro Nakazato ${ }^{3}$, Yuichiro Hirai², Yoko Kubosawa², Yukie Sunata², Misako Matsushita², Toshio Uraoka²

Institutions

1 Division of Research and Development for Minimally Invasive Treatment, Cancer Center, Keio University School of Medicine, Tokyo, Japan

2 Department of Gastroenterology, National Hospital Organization Tokyo Medical Center, Tokyo, Japan

3 Center for Diagnostic and Therapeutic Endoscopy, Keio University School of Medicine, Tokyo, Japan

submitted 30.1.2018

accepted after revision 25.4.2018

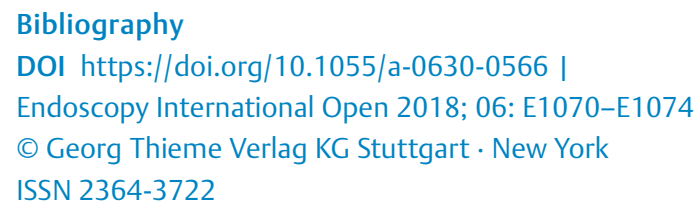

Corresponding author

Toshio Uraoka, MD, PhD, Department of Gastroenterology, National Hospital Organization Tokyo Medical Center, 2-5-1 Higashigaoka, Meguro-ku, Tokyo 152-8902, JAPAN

Fax: +81-3-5363-3967

toshi_urao@yahoo.co.jp

\section{ABSTRACT}

Background and study aims We developed a new endoscopic closure technique using just conventional endoclips. The feasibility of endoscopic mucosa-submucosa clip closure method was evaluated in this clinical pilot study.

Patients and methods This study involved consecutive 25 patients who underwent colorectal endoscopic submucosal dissection. Endoclips were placed at the edge of the mucosal defect. Each arm of the endoclip gripped the mucosa and submucosa, respectively. The direction in which the endoclip grips were placed was parallel to the short axis of the defect. Several endoclips were applied in this way. As a result, the mucosal defect was significantly reduced in size. Additional clips were placed to achieve complete closure.

Results Mean size of resected specimen was $31.2 \pm 11 \mathrm{~mm}$. The success rate was $96 \%$ (24/25). Mean procedure time was $9.6 \pm 4.4$ minutes. Mean number of endoclips was $9.3 \pm 3.7$. No complications were observed in any of the patients after the procedure.

Conclusion Endoscopic mucosa-submucosa clip closure method could close mucosal defect of size around $2-4 \mathrm{~cm}$ completely using just conventional endoclips, and it seems easy, simple and low cost.

\section{Introduction}

Recently, endoscopic submucosal dissection (ESD) has been gaining acceptance as an alternative to endoscopic mucosal resection (EMR) with a high possibility of en bloc complete resection without limitation of lesion size [1 -4]. Even when ESD is successful, there is a risk of delayed perforation or bleeding. Incidence of delayed perforation and postoperative bleeding following colorectal ESD are $0.2 \%$ to $0.4 \%[5,6]$ and $0.7 \%$ to $2.2 \%$, [7-9] respectively. Furthermore, postoperative bleeding rates in patients receiving antithrombotic agents were reported to range from $22.5 \%$ to $25 \%[10,11]$. Several recent studies advocated closure of the defects after EMR and ESD with endoclips to prevent delayed adverse events $[12,13]$. Liaquat et al. reported that closure after EMR (lesions $>2 \mathrm{~cm}$ ) drastically decreased incidence of delayed hemorrhage from $9.7 \%$ to $1.8 \%$.
However, the size of the mucosal defect after ESD is relatively large compared with the size after EMR, making it difficult to achieve complete closure using only conventional endoclips.

Several useful methods have been reported such as endoscopic purse-string suture [14], slip knot clip suturing method [15-17], string clip suturing method $[18,19]$, and "loop clip" [20]. However, these methods need endo-loop, double-channel endoscope, string, or supplement devices. We previously reported a closure method using just conventional clips [21]. Here, we report results of a clinical pilot study of the endoscopic mucosa-submucosa clip closure method. 

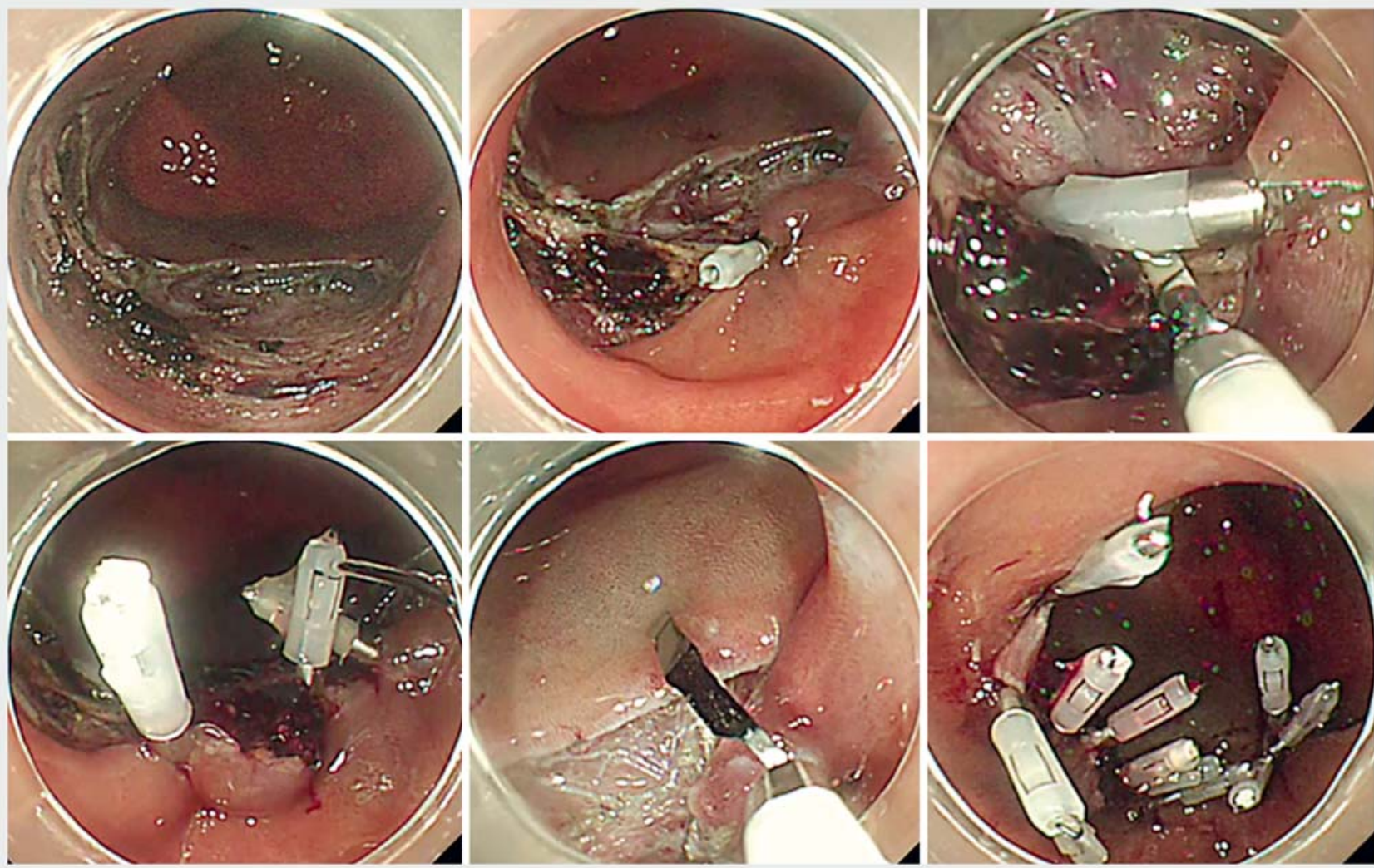

- Fig. 1 Mucosa-submucosa clip closure method. (Upper left) A mucosal defect after colonic endoscopic submucosal dissection. (Upper middle) The first endoclip was placed at the edge of the mucosal defect. Each arm of the endoclip hooked mucosa and submucosa, respectively. The direction of the endoclips was parallel to the short axis of the defect. (Upper right) The second endoclip was also applied in this way. (Lower left) The third endoclip was placed and the mucosal defect was significantly reduced in size. (Lower middle) The fourth clip hooked both sides of the mucosa. (Lower right) Additional endoclips were placed to achieve complete closure.

\section{Patients and methods}

\section{Patients}

The current study involved 25 consecutive patients who underwent colorectal ESD at Tokyo Medical Center between May 2017 and February 2018. Exclusion criteria were as follows: (1) tumor more than $6 \mathrm{~cm}$; (2) immediate perforation during ESD; (3) lesions extending to anus or ileocecal valve; and (4) presence of clinically significant underlying disease (serious cardiopulmonary, hepatic or renal disease). This study protocol was approved by the Institutional Review Board of Tokyo Medical Center (the registration number: R17-096), and written informed consent was obtained from all patients.

\section{Mucosa-submucosa clip closure method}

Endoclips (EZ Clip, HX-610-090 L [long-type], OLYMPUS, Tokyo, Japan) were placed at the edge of the mucosal defect after colorectal ESD. Each arm of the endoclip gripped the mucosa and submucosa, respectively. The direction of the endoclip grip was parallel to the short axis of the defect. Several endoclips were applied in this way. As a result, the mucosal defect was significantly reduced in size. Then, additional endoclips could be applied to both sides of the mucosal defect. Several endoclips were required to achieve complete closure ( $\vee$ Fig.1). Finally, endoscopic inspection was performed to visually confirm complete closure. A single-channel endoscope was used in this study.

\section{Evaluation of the procedure}

We evaluated success rate, mean procedure time, number of clips and adverse events (AEs). Success rate was defined as the percentage of success (complete closure of mucosal defect) among a number of enrolled patients. "Complete closure of mucosal defect" was defined as complete closure of the whole resection site with clips. Procedure time was measured from insertion of first clip to completion of the procedure. Delayed perforation was defined as no perforation during ESD and no symptoms immediately after tumor removal with subsequent sudden appearance of abdominal pain with free air on X-ray. The definition of delayed bleeding was bleeding symptom or hemoglobin loss ( $\geq 2 \mathrm{~g} / \mathrm{dL})$.

\section{Statistics}

All continuous variables were expressed as mean \pm standard deviation. 
- Table 1 Characteristics of and outcomes in patients.

\begin{tabular}{|c|c|c|c|c|c|c|}
\hline Patient no. & Sex & Age (y) & Location & Size of resected specimen $(\mathrm{mm})$ & Procedure time (min) & Number of clips \\
\hline 1 & $\mathrm{~F}$ & 57 & Sigmoid & 27 & 6 & 8 \\
\hline 2 & $\mathrm{~F}$ & 79 & Rectum & 20 & 10 & 8 \\
\hline 3 & M & 59 & Rectum & 35 & 3.2 & 4 \\
\hline 4 & M & 47 & Sigmoid & 29 & 11.8 & 11 \\
\hline 5 & M & 67 & Transverse & 19 & 17.5 & 8 \\
\hline 6 & $\mathrm{~F}$ & 72 & Ascending & 25 & 2.8 & 2 \\
\hline 7 & M & 71 & Transverse & 25 & 17 & 13 \\
\hline 8 & M & 62 & Sigmoid & 25 & 6 & 6 \\
\hline 9 & M & 66 & Rectum & 57 & 18 & 16 \\
\hline 10 & $\mathrm{~F}$ & 68 & Descending & 32 & 10 & 9 \\
\hline 11 & $\mathrm{~F}$ & 61 & Transverse & 34 & 9 & 12 \\
\hline 12 & M & 41 & Rectum & 31 & 8 & 9 \\
\hline 13 & $\mathrm{~F}$ & 68 & Sigmoid & 60 & 11.8 & 13 \\
\hline 14 & M & 64 & Descending & 42 & 11.3 & 11 \\
\hline 15 & $\mathrm{~F}$ & 81 & Sigmoid & 27 & 9 & 9 \\
\hline 16 & M & 63 & Descending & 46 & 15 & 19 \\
\hline 17 & M & 77 & Sigmoid & 26 & 7.7 & 8 \\
\hline 18 & $\mathrm{~F}$ & 79 & Transverse & 25 & 7.8 & 10 \\
\hline 19 & M & 65 & Ascending & 32 & 7.5 & 9 \\
\hline 20 & $\mathrm{~F}$ & 41 & Transverse & 18 & 7.5 & 8 \\
\hline 21 & M & 70 & Transverse & 33 & 8.4 & 9 \\
\hline 22 & M & 54 & Sigmoid & 20 & 2.3 & 4 \\
\hline 23 & M & 65 & Sigmoid & 27 & 11.5 & 10 \\
\hline 24 & M & 80 & Transverse & 30 & 15 & 10 \\
\hline 25 & $M$ & 75 & Ascending & 34 & 4.7 & 6 \\
\hline
\end{tabular}

\section{Results}

Characteristics of and outcomes in the 25 patients are summarized in $>$ Table 1 . Mean age was $65 \pm 11$ years. Mean size of resected specimen was $31.2 \pm 10.6 \mathrm{~mm}$. In 24 of 25 patients (96\%), complete closure was achieved with the mucosa-submucosa clip closure method.

The mucosa-submucosa clip closure method failed in one case (patient no. 13), in which the lesion was located at a flexure of the sigmoid colon, and the size was $60 \mathrm{~mm}$. Although approximately $80 \%$ of the mucosal defect was closed with 13 clips, the mucosal defect was partially left open.

Mean procedure time was $9.6 \pm 4.4$ minutes. Mean number of endoclips was $9.3 \pm 3.7$. The rate of complications such as postoperative bleeding and perforation was $0 \%$.

\section{Discussion}

In the current study, our newly developed closure technique, endoscopic mucosa-submucosa clip closure method, was successfully carried out on most of the patients with an acceptable procedure time. Our results indicate that the endoscopic mucosa-submucosa clip closure method is a feasible technique for closing mucosal defects that measure 2 to $4 \mathrm{~cm}$ after colorectal ESD.

The efficacy of clipping for preventing AEs after colorectal ESD is still controversial [22]. However, it would be effective to perform prophylactic clipping in patients at high risk of AEs. The endoscopic mucosa-submucosa clip closure method may be a promising option for patients with muscle layer injury or perforation during colorectal ESD, and patients who are taking antithrombotic drugs. 
Mean procedure time in this study was $9.6 \pm 4.4$ minutes. Wang et al. reported that mean procedure time was 13.5 minutes (range 8-20) for endoscopic purse-string suture [23]. We previously reported that mean procedure time was $18.2 \pm 3.3$ minutes for "slip knot clip suturing method" [17], and $23.4 \pm 13.8$ minutes for "string clip suturing method" [19]. String-assisted closure techniques sometimes are stuck by a tangle of the string. The endoscopic mucosa-submucosa clip closure method is simple without string or a special device, and procedure time seems relatively short.

There are some reports of endoscopic closure for large mucosal defects. These include endoscopic purse-string suture $[14,23]$, use of the Overstitch endoscopic suturing system (Apollo Endosurgery Inc, United States)[24], and over-the scope clip (OTSC) system (Ovesco Endoscopy, Germany) [25, 26]. The cost of the OTSC system ${ }^{\circledR}$ is $¥ 79800$ (US\$725). The average cost of mucosa-submucosa clip closure method per patient was US\$75.6 (9.3 clips per patient).

Complete closure of a mucosal defect measuring less than $30 \mathrm{~mm}$ is not so difficult with the conventional endoclip method. In the conventional endoclip method, each arm of the endoclip grips mucosa and mucosa (both sides of the mucosal defect). However, one arm of the endoclip often slips from the mucosa. The failed clip is useless and hampers the next step. Such situation might be stressful for an endoscopist. With the endoscopic mucosa-submucosa clip closure method, each arm of the endoclip grips the mucosa and submucosa, respectively. Neither arm of the endoclip slips, and clipping would be the result that an endoscopist expects. Therefore, stress for the endoscopist is eliminated.

This feasibility trial is limited by its small sample size. We did not evaluate the superiority over other methods. However, the high procedural success rate and relatively short procedure time showed the method's technical feasibility. One of two

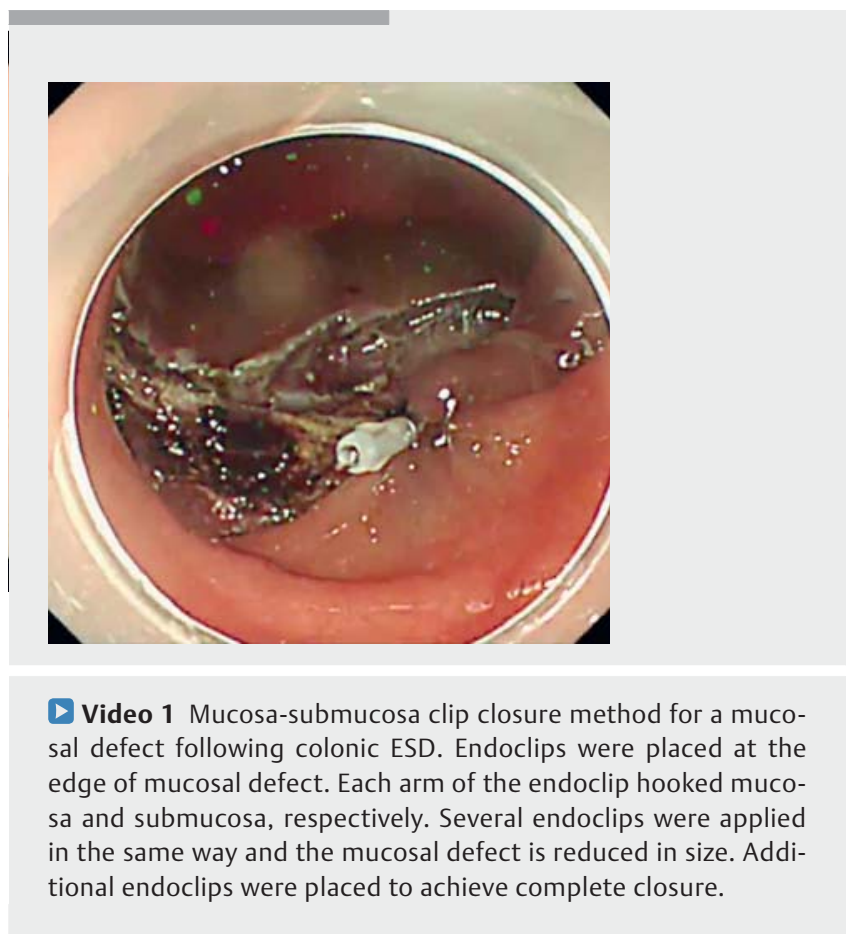

large mucosal defects larger than $5 \mathrm{~cm}$ could not be closed completely in this study. This method is not appropriate for a large mucosal defect. Although the rate of complete closure of large mucosal defect was low in this study, further examination is needed.

\section{Conclusion}

In conclusion, the endoscopic mucosa-submucosa clip closure method was effective for complete closure of mucosal defects measuring 2 to $4 \mathrm{~cm}$ using just conventional endoclips, and it seems easy, simple and low cost. However, the utility and safety of this method will need to be verified in a large comparative study.

\section{Acknowledgement}

This study was supported by a grant from the National Hospital Organization (No.H29-NHO [gastroenterology], to T.U.).

\section{Competing interests}

None

\section{References}

[1] Kinoshita S, Uraoka T, Nishizawa T et al. The role of colorectal endoscopic submucosal dissection in patients with ulcerative colitis. Gastrointest Endosc 2018; 87: 1079-1084

[2] Uraoka T, Parra-Blanco A, Yahagi N. Colorectal endoscopic submucosal dissection in Japan and Western countries. Dig Endosc 2012; 24: (Suppl. 01): $80-83$

[3] Nishizawa T, Uraoka T, Suzuki H et al. Control of the treatment device for endoscopy by the left hand: two-fingers method. Gastrointest Endosc 2014; 80: $1206-1207$

[4] Nishizawa T, Uraoka T, Suzuki $\mathrm{H}$ et al. Control of tip deflection by right pinkie shaft grip: right pinkie maneuver. Gastrointest Endosc 2014; 80: 1208

[5] Saito Y, Uraoka T, Yamaguchi Y et al. A prospective, multicenter study of 1111 colorectal endoscopic submucosal dissections (with video). Gastrointest Endosc 2010; 72: 1217-1225

[6] Arezzo A, Passera R, Marchese $N$ et al. Systematic review and meta-analysis of endoscopic submucosal dissection vs endoscopic mucosal resection for colorectal lesions. United European Gastroenterol J 2016; 4: $18-29$

[7] Kobayashi N, Yoshitake N, Hirahara Y et al. Matched case-control study comparing endoscopic submucosal dissection and endoscopic mucosal resection for colorectal tumors. J Gastroenterol Hepatol 2012; 27: $728-733$

[8] Fujishiro M, Yahagi N, Kakushima N et al. Outcomes of endoscopic submucosal dissection for colorectal epithelial neoplasms in 200 consecutive cases. Clin Gastroenterol Hepatol 2007; 5: 678-683; quiz 45

[9] Isomoto H, Nishiyama H, Yamaguchi N et al. Clinicopathological factors associated with clinical outcomes of endoscopic submucosal dissection for colorectal epithelial neoplasms. Endoscopy 2009; 41: $679-683$

[10] Ono S, Fujishiro M, Yoshida $\mathrm{N}$ et al. Thienopyridine derivatives as risk factors for bleeding following high risk endoscopic treatments: Safe 
Treatment on Antiplatelets (STRAP) study. Endoscopy 2015; 47: 632 637

[11] Akimoto T, Goto O, Nishizawa T et al. Endoscopic closure after intraluminal surgery. Dig Endosc 2017; 29: 547 - 558

[12] Liaquat H, Rohn E, Rex DK. Prophylactic clip closure reduced the risk of delayed postpolypectomy hemorrhage: experience in 277 clipped large sessile or flat colorectal lesions and 247 control lesions. Gastrointest Endosc 2013; 77: 401 - 407

[13] Otake Y, Saito Y, Sakamoto T et al. New closure technique for large mucosal defects after endoscopic submucosal dissection of colorectal tumors (with video). Gastrointest Endosc 2012; 75: 663-667

[14] Matsuda T, Fujii T, Emura F et al. Complete closure of a large defect after EMR of a lateral spreading colorectal tumor when using a twochannel colonoscope. Gastrointest Endosc 2004; 60: 836-838

[15] Nishizawa T, Uraoka T, Suzuki H et al. New endoscopic suturing method: slip knot clip suturing. Gastrointest Endosc 2015; 82: 570 571

[16] Nishizawa T, Uraoka T, Sagara S et al. Endoscopic slipknot clip suturing method: an ex vivo feasibility study (with video). Gastrointest Endosc 2016; 83: 447-450

[17] Nishizawa T, Ochiai Y, Uraoka T et al. Endoscopic slip-knot clip suturing method: prospective pilot study (with video). Gastrointest Endosc 2017; 85: $433-437$

[18] Yahagi N, Nishizawa T, Akimoto T et al. New endoscopic suturing method: string clip suturing method. Gastrointest Endosc 2016; 84: $1064-1065$
[19] Nishizawa T, Akimoto T, Uraoka T et al. Endoscopic string clip suturing method: a prospective pilot study (with video). Gastrointest Endosc 2018; 87: $1074-1078$

[20] Osada T, Sakamoto N, Ritsuno H et al. Process of wound healing of large mucosal defect areas that were sutured by using a loop clip-assisted closure technique after endoscopic submucosal dissection of a colorectal tumor. Gastrointest Endosc 2013; 78: 793 - 798

[21] Banno S, Nishizawa T, Kinoshita $S$ et al. Endoscopic mucosa-submucosal clip closure method. Endoscopy 2017; 49: E307-E308

[22] Nishizawa T, Suzuki H, Goto O et al. Effect of prophylactic clipping in colorectal endoscopic resection: A meta-analysis of randomized controlled studies. United European Gastroenterol J 2017; 5: 859-867

[23] Wang ], Zhao L, Wang $X$ et al. A novel endoloop system for closure of colonic mucosal defects through a single-channel colonoscope. Endoscopy 2017; 49: 803-807

[24] Kantsevoy SV, Bitner M, Mitrakov AA et al. Endoscopic suturing closure of large mucosal defects after endoscopic submucosal dissection is technically feasible, fast, and eliminates the need for hospitalization (with videos). Gastrointest Endosc 2014; 79: 503 - 507

[25] Hochberger J, Wedi E, Tchoumak I et al. Over-the-scope clip placement and endosponge insertion for prevention of pancreatic enzymeinduced duodenal damage after large duodenal endoscopic resection. Endoscopy 2016; 48: E401 - E402

[26] von Renteln D, Schmidt A, Vassiliou MC et al. Endoscopic closure of large colonic perforations using an over-the-scope clip: a randomized controlled porcine study. Endoscopy 2009; 41: 481-486 